\title{
Halogenated Dihydropyrrol-2-One Molecules Inhibit Pyocyanin Biosynthesis by Blocking the Pseudomonas Quinolone Signaling System
}

\author{
Theerthankar Das ${ }^{1, *,+}$, Shekh Sabir ${ }^{2,+} \mathbb{D}$, Ren Chen ${ }^{2} \mathbb{D}$, Jessica Farrell ${ }^{1,3}$, Frederik H. Kriel ${ }^{3}$, \\ Gregory S. Whiteley ${ }^{3}{ }^{(D}$, Trevor O. Glasbey ${ }^{3}$, Jim Manos ${ }^{1} \mathbb{D}$, Mark D. P. Willcox ${ }^{4}$ and Naresh $_{\text {Kumar }}{ }^{2} \mathbb{D}$
}

1 Infection, Immunity and Inflammation, Charles Perkins Centre, Sydney Institute for Infectious Diseases, School of Medical Sciences, The University of Sydney, Sydney, NSW 2006, Australia; jessica.farrell@sydney.edu.au (J.F.); jim.manos@sydney.edu.au (J.M.)

2 School of Chemistry, The University of New South Wales, Sydney, NSW 2052, Australia; s.sabir@student.unsw.edu.au (S.S.); r.chen@unsw.edu.au (R.C.); n.kumar@unsw.edu.au (N.K.)

3 Whiteley Corporation, 19-23 Laverick Avenue, Tomago, NSW 2322, Australia; erik.kriel@whiteley.com.au (F.H.K.); greg.whiteley@whiteley.com.au (G.S.W.); trevor.glasbey@whiteley.com.au (T.O.G.)

4 School of Optometry and Vision Science, The University of New South Wales, Sydney, NSW 2052, Australia; m.willcox@unsw.edu.au

* Correspondence: das.ashishkumar@sydney.edu.au

+ These authors contributed equally to this work.

Citation: Das, T.; Sabir, S.; Chen, R.; Farrell, J.; Kriel, F.H.; Whiteley, G.S.; Glasbey, T.O.; Manos, J.; Willcox, M.D.P.; Kumar, N. Halogenated Dihydropyrrol-2-One Molecules Inhibit Pyocyanin Biosynthesis by Blocking the Pseudomonas Quinolone Signaling System. Molecules 2022, 27, 1169. https://doi.org/10.3390/ molecules27041169

Academic Editor: Changsheng Zhang

Received: 25 December 2021

Accepted: 4 February 2022

Published: 9 February 2022

Publisher's Note: MDPI stays neutral with regard to jurisdictional claims in published maps and institutional affiliations.

Copyright: () 2022 by the authors Licensee MDPI, Basel, Switzerland. This article is an open access article distributed under the terms and conditions of the Creative Commons Attribution (CC BY) license (https:/ / creativecommons.org/licenses/by/ $4.0 /)$.

\begin{abstract}
Quorum-sensing (QS) systems of Pseudomonas aeruginosa are involved in the control of biofilm formation and virulence factor production. The current study evaluated the ability of halogenated dihydropyrrol-2-ones (DHP) (Br (4a), Cl (4b), and F (4c)) and a non-halogenated version (4d) to inhibit the QS receptor proteins LasR and PqsR. The DHP molecules exhibited concentrationdependent inhibition of LasR and PqsR receptor proteins. For LasR, all compounds showed similar inhibition levels. However, compound $4 \mathrm{a}(\mathrm{Br})$ showed the highest decrease (two-fold) for PqsR, even at the lowest concentration $(12.5 \mu \mathrm{g} / \mathrm{mL})$. Inhibition of QS decreased pyocyanin production amongst P. aeruginosa PAO1, MH602, ATCC 25619, and two clinical isolates (DFU-53 and 364707). In the presence of DHP, P. aeruginosa ATCC 25619 showed the highest decrease in pyocyanin production, whereas clinical isolate DFU-53 showed the lowest decrease. All three halogenated DHPs also reduced biofilm formation by between 31 and $34 \%$. The non-halogenated compound $4 \mathrm{~d}$ exhibited complete inhibition of LasR and had some inhibition of PqsR, pyocyanin, and biofilm formation, but comparatively less than halogenated DHPs.
\end{abstract}

Keywords: P. aeruginosa; pyocyanin; dihydropyrrol-2-one; LasR; PQS; quorum sensing

\section{Introduction}

Pseudomonas aeruginosa is an opportunistic Gram-negative bacterium that is acknowledged as a critical pathogen by the World Health Organisation (WHO) [1]. P. aeruginosa is often multi-drug resistant, forms robust biofilms on biotic and abiotic surfaces, and is responsible for substantial morbidity and mortality in immunocompromised patients (especially those with Cystic Fibrosis or HIV infection) [2]. This bacterium is also the leading cause of nosocomial infections relating to ventilator-associated pneumonia, urinary tract, burns, wounds, and skin and soft tissue infections in hospitalized patients [2].

Biofilm formation and virulence factor production in P. aeruginosa is controlled by various signaling systems within P. aeruginosa including quorum sensing (QS) systems [3]. QS refers to population-dependent bacterial cell-to-cell signaling that can upregulate or downregulate certain genes that would favor bacterial survival, fitness, virulence factor production, pathogenicity in the host, biofilm formation, and resistance to antimicrobial agents. 
In P. aeruginosa, QS is driven by four signaling networks, LasI/LasR-AHL, RhlI/RhlR-BHL, PqsR-PQS, and IqsR-IQS [3]. LasR, RhlR, PqsR, and IqsR are transcriptional regulator receptors that bind to their respective autoinducer molecules (AHL, BHL, PQS, and IQS). These QS systems are arranged in hierarchies, with the LasI/R-AHL system often at the top of the hierarchy [3]. The LasI/R-AHL is involved in the regulation of production of protease and elastase; the RhlI/R-BHL system regulates elastase and rhamnolipid production; and the PqsR-PQS system regulates phenazine (predominantly pyocyanin) biosynthesis [4]. Pyocyanin is a virulence factor secreted by P. aeruginosa in the late exponential phase via PqsR-PQS mediated activation of phzA1-G1 and phzA2-G2 operons [3,4].

The sputum of cystic fibrosis and bronchitis patients contains between $16.5 \mu \mathrm{g} / \mathrm{mL}$ and $27.3 \mu \mathrm{g} / \mathrm{mL}$ of pyocyanin, and exudates of infected wound dressing from patients with burn injuries contain up to $5.3 \mu \mathrm{g} / \mathrm{g}$ (mean $2.0 \pm 2.3 \mu \mathrm{g} / \mathrm{g}$ ) of pyocyanin $[5,6]$. Pyocyanin induces severe oxidative stress in host cells by producing reactive oxygen species such as hydrogen peroxide, depletes mammalian intracellular antioxidant (glutathione) levels, enhances the release of interleukin-8 (IL-8), and induces neutrophil-mediated tissue damage [7-9]. Pyocyanin can also induce premature cellular senescence (cell cycle arrest) in human diploid fibroblasts and, consequently, impairs wound repair [6]. Another crucial role of pyocyanin, discovered by Das et al., in 2015, is binding to DNA via intercalation with nitrogenous bases [10]. P. aeruginosa produces extracellular DNA (eDNA) as a major part of its biofilm formation [11]. Pyocyanin can bind to this eDNA to reduce its loss to the external environment [12]. Pyocyanin also aids in the establishment of the P. aeruginosa biofilm matrix and robust biofilms [12]. Pyocyanin can also facilitate electron transfer as the result of its binding to DNA, which might support the metabolic activity of bacterial subpopulations within biofilms [12].

Strategies that inhibit QS are being investigated as potential control mechanisms for various pathogens, considering the rise in bacterial antibiotic resistance and the development of superbugs. One strategy to combat QS is the synthesis of derivatives of lactone-based molecules, such as furanones and their analogues, that mimic the $N$-acyl homoserine lactones, which are the natural ligands in the P. aeruginosa LasR/LasI and RhlI/RhlR QS systems $[13,14]$. In this study, we synthesized halogenated dihydropyrrol2-one (DHP) based homoserine lactone mimics. The structure of DHPs partly resembled AHL signaling molecules, and previous studies have demonstrated that DHPs possess both a six-membered pendant aromatic ring and a five-membered lactam ring and contain a conjugated exocyclic double bond, exhibit good LasR antagonist activity [15]. In our previous reports, we have synthesized several different analogues of DHP by modification at the nitrogen atom and substitution on the phenyl ring and on the exocyclic double bond, and these studies demonstrated that the exocyclic double bond and halogenated phenyl ring were essential for interfering with the LasR-AHL system $[15,16]$. In the current study, we tested these halogenated DHP compounds for their inhibition of the PQS QS by inhibiting PqsR receptor protein using a GFP-tagged P. aeruginosa PAO1 strain. We also tested these synthesized DHP compounds for their impact on pyocyanin production and biofilm formation with both laboratory and clinical isolates from infected wounds.

\section{Results}

\subsection{Susceptibility of P. aeruginosa Isolates to Ciprofloxacin}

Figure 1 shows the minimum inhibitory concentration (MIC) of $P$. aeruginosa. Strains PAO1-PQS, ATCC 25619 and the clinical isolate 364707 were sensitive to $\leq 1 \mu \mathrm{g} / \mathrm{mL}$ ciprofloxacin. The MIC for isolates MH602 and DFU-53 was $2 \mu \mathrm{g} / \mathrm{mL}$. Data represent the average from three biological replicates. 


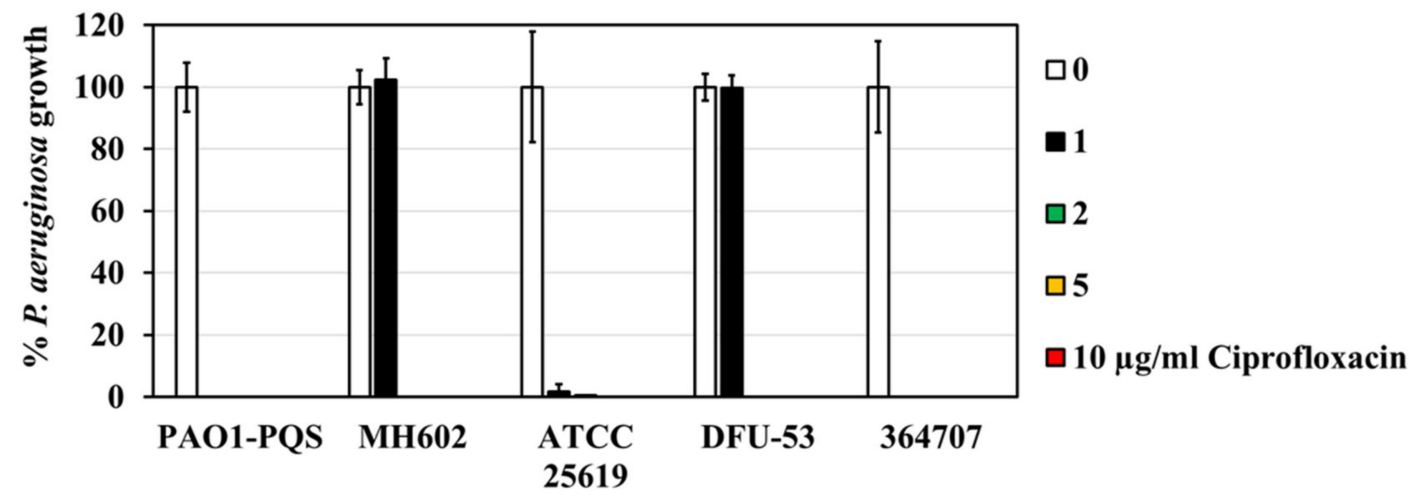

Strains of $P$. aeruginosa

Figure 1. The susceptibility of P. aeruginosa isolates to ciprofloxacin.

\subsection{DHP Compound Inhibition of LasR}

Figure 2 details the expression of the LasR QS system of P. aeruginosa MH602, determined using the level of GFP fluorescence measured at $E_{485 \mathrm{~nm}}$ and $E_{535 \mathrm{~nm}}$. In the controls, LasR-mediated GFP production peaked after $4 \mathrm{~h}$ and plateaued thereafter. This was also similar, although slightly delayed, when ethanol, the solvent for the DHP compounds, was present (Figure 2). Both halogenated and non-halogenated DHP compounds showed a concentration-dependent decrease in LasR receptor-mediated GFP production. In the presence of all four DHP compounds, the GFP produced as a function of the number of $P$. aeruginosa $\mathrm{MH602}$ cells $\left(\mathrm{OD}_{600 \mathrm{~nm}}\right)$ was significantly decreased $(p<0.05)$. Increasing the concentration of any DHP compounds increased the inhibition of GFP production via the Las pathway. The greatest inhibition occurred with compounds $4 \mathbf{a}$ (Br) and $\mathbf{4 d}$. At $50 \mu \mathrm{g} / \mathrm{mL}$, all compounds showed complete inhibition of GFP fluorescence. Data represent the average from three biological replicates.
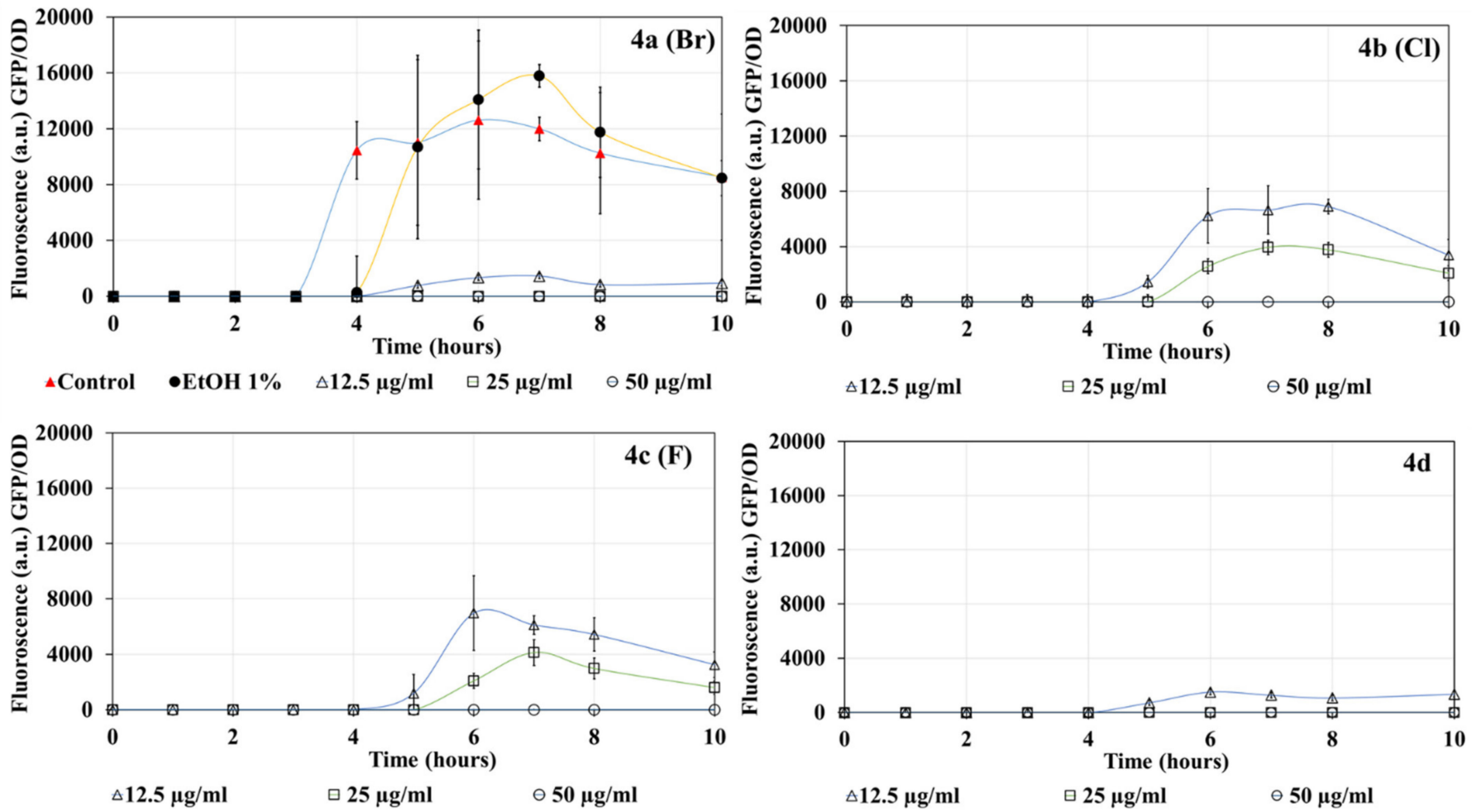

Figure 2. Effects of DHP compounds $(12.5-50 \mu \mathrm{g} / \mathrm{mL})$ on the production of GFP mediated through LasR in P. aeruginosa MH602. 


\subsection{Inhibition of PqsR by DHP Compounds}

Figure 3 shows the GFP fluorescence levels produced by activation of the PqsR QS system in P. aeruginosa PAO1-PQS. In the controls, PqsR-mediated production of GFP, began after one hour and peaked at $5 \mathrm{~h}$. Both halogenated and non-halogenated DHP compounds showed a concentration-dependent decrease in PqsR receptor-mediated GFP over the $10 \mathrm{~h}$ of growth. Compared to the ethanol control, $12.5 \mu \mathrm{g} / \mathrm{mL}$ of compound $4 \mathbf{a}(\mathbf{B r})$ reduced the production of PQS-mediated GFP after 5 and $6 \mathrm{~h}$, and $25-50 \mu \mathrm{g} / \mathrm{mL}$ delayed the production of PQS-mediated GFP and reduced its production between 4 and $10 \mathrm{~h}$. Compounds $4 \mathbf{b}(\mathbf{C l})$ and $4 \mathbf{d}$ were less effective than $4 \mathbf{a}(\mathbf{B r})$, with $12.5 \mu \mathrm{g} / \mathrm{mL}$ delaying the production of PQS-mediated GFP but having no effect on GFP production after $4 \mathrm{~h}$. Compound 4c (F) delayed the production of PQS-mediated GFP at all concentrations tested, and 25 to $50 \mu \mathrm{g} / \mathrm{mL}$ reduced production between 2 and $10 \mathrm{~h}$ of growth. Data represent the average from three biological replicates.
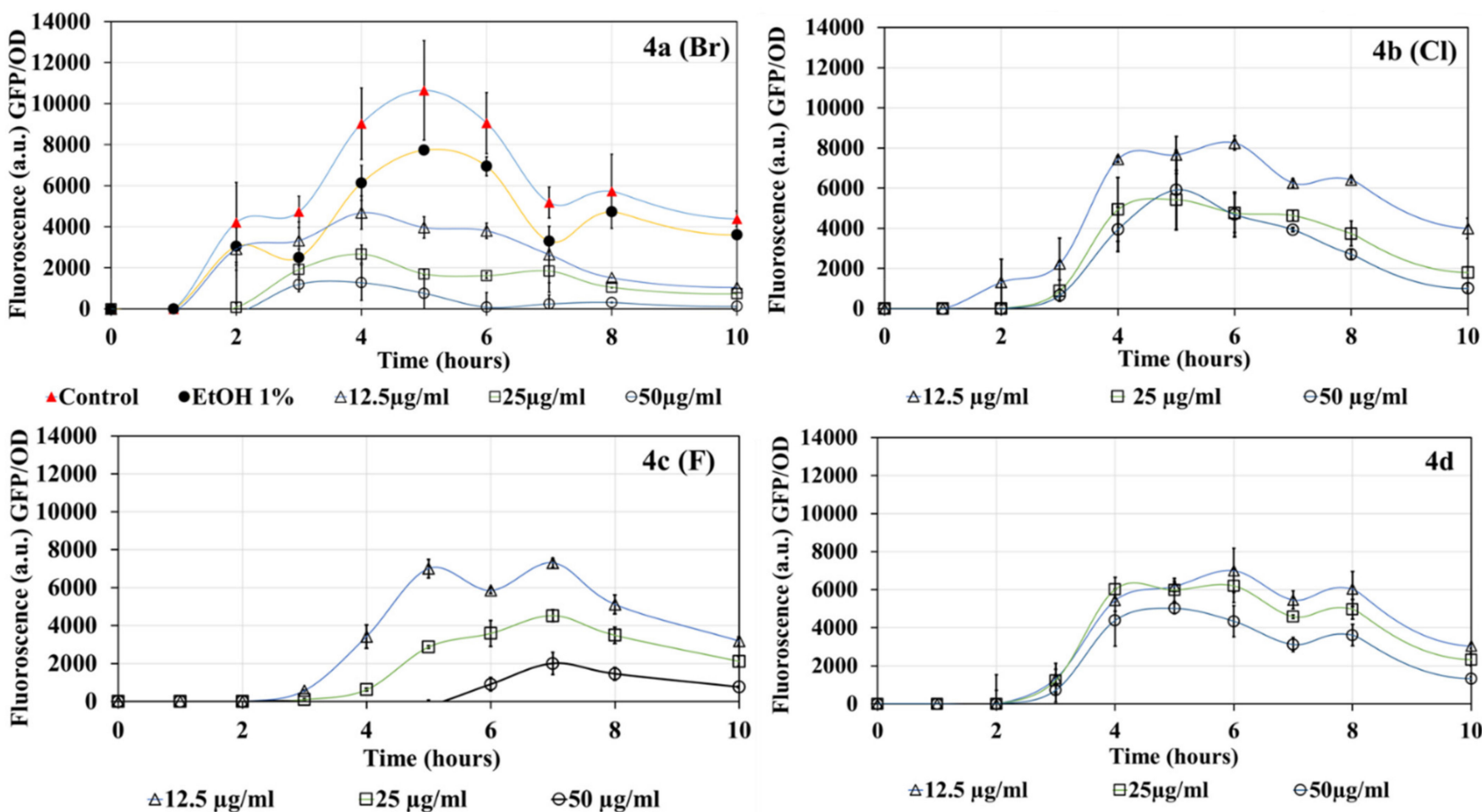

Figure 3. Effects of DHP compounds on PQS-linked GFP production by P. aeruginosa PAO1.

\subsection{Effects of DHPs Compounds on Planktonic Growth of P. aeruginosa}

In general, DHP compounds showed minimal effect on the planktonic growth of $P$. aeruginosa strains, which is expected from quorum sensing inhibitors (QSIs). For all strains, there were slight reductions in growth $(20 \%)$ at the highest concentration $(50 \mu \mathrm{g} / \mathrm{mL})$ of all DHP compounds. However, these differences in bacterial growth in the presence of DHP compounds were not statistically significant in comparison to controls. Growth data are representative of the average from three biological replicates (Figure 4A,B). 

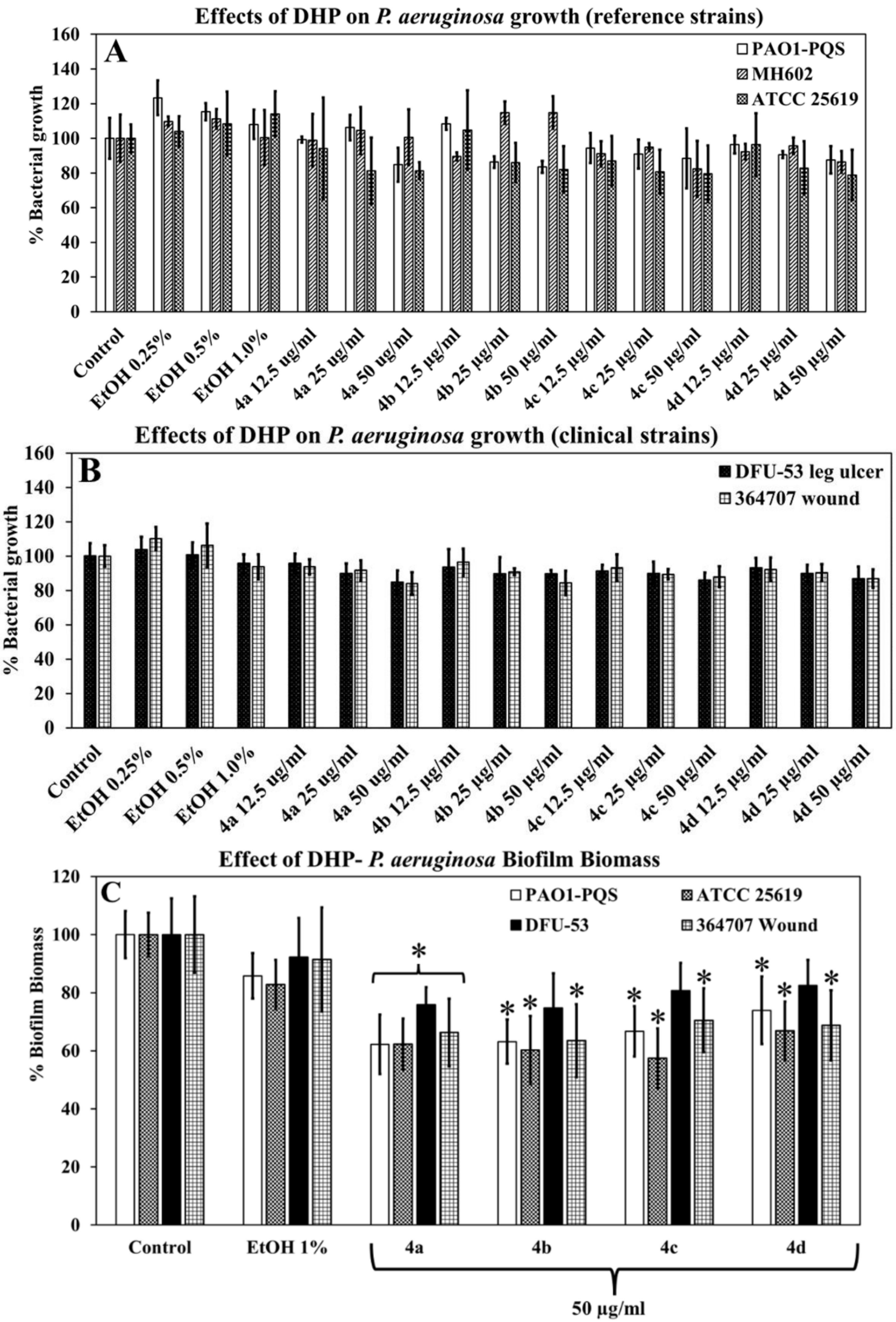

Figure 4. (A,B) Effect of DHP compounds on P. aeruginosa planktonic growth. (C) Effect of DHP compounds on $P$. aeruginosa biofilm biomass formation. * Indicates differences are statistically significant $p<0.05$. 


\subsection{Effects of DHPs on Biofilm Formation by P. aeruginosa}

P. aeruginosa strains PAO1-PQS, ATCC 25619, and DFU-53, grown in the presence of $50 \mu \mathrm{g} / \mathrm{mL}$ of any DHP compound, had a significant decrease in biofilm biomass (Figure 4C) of between 16 and $43 \%$ in comparison to control. However, the biofilm formation by strain DFU-53 was only affected by compound $4 a$. In the presence of solvent alone ( $1 \%$ ethanol), the biofilm formation of all P. aeruginosa strains was not significantly reduced (reduced by 8-17\%). Biofilm biomass data are representative of the average from four biological replicates.

\subsection{DHP Impedes Pyocyanin Production by P. aeruginosa Strains}

Both halogenated and non-halogenated DHP compounds showed concentrationdependent decreases in pyocyanin production after $48 \mathrm{~h}$ of growth with all strains (Figure 5). For example, in the presence of DHPs, the production of pyocyanin from PAO1-PQS was reduced by $61-25 \%$ for $4 \mathrm{a}, 83-40 \%$ for $4 \mathrm{~b}, 68-21 \%$ for $4 \mathrm{c}$, and $90-59 \%$ for $4 \mathrm{~d}$ in comparison to the controls, for isolates PAO1-PQS, MH602, ATCC 25619, and 364707. However, isolate DFU-53 from a foot ulcer showed reduced effects of the DHPs, but pyocyanin production was reduced by approximately $45 \%$ for compounds at $50 \mu \mathrm{g} / \mathrm{mL}$. Refer Supplementary Table S1 for pyocyanin production quantification. Data represent the average from $n=3$ biological replicates.
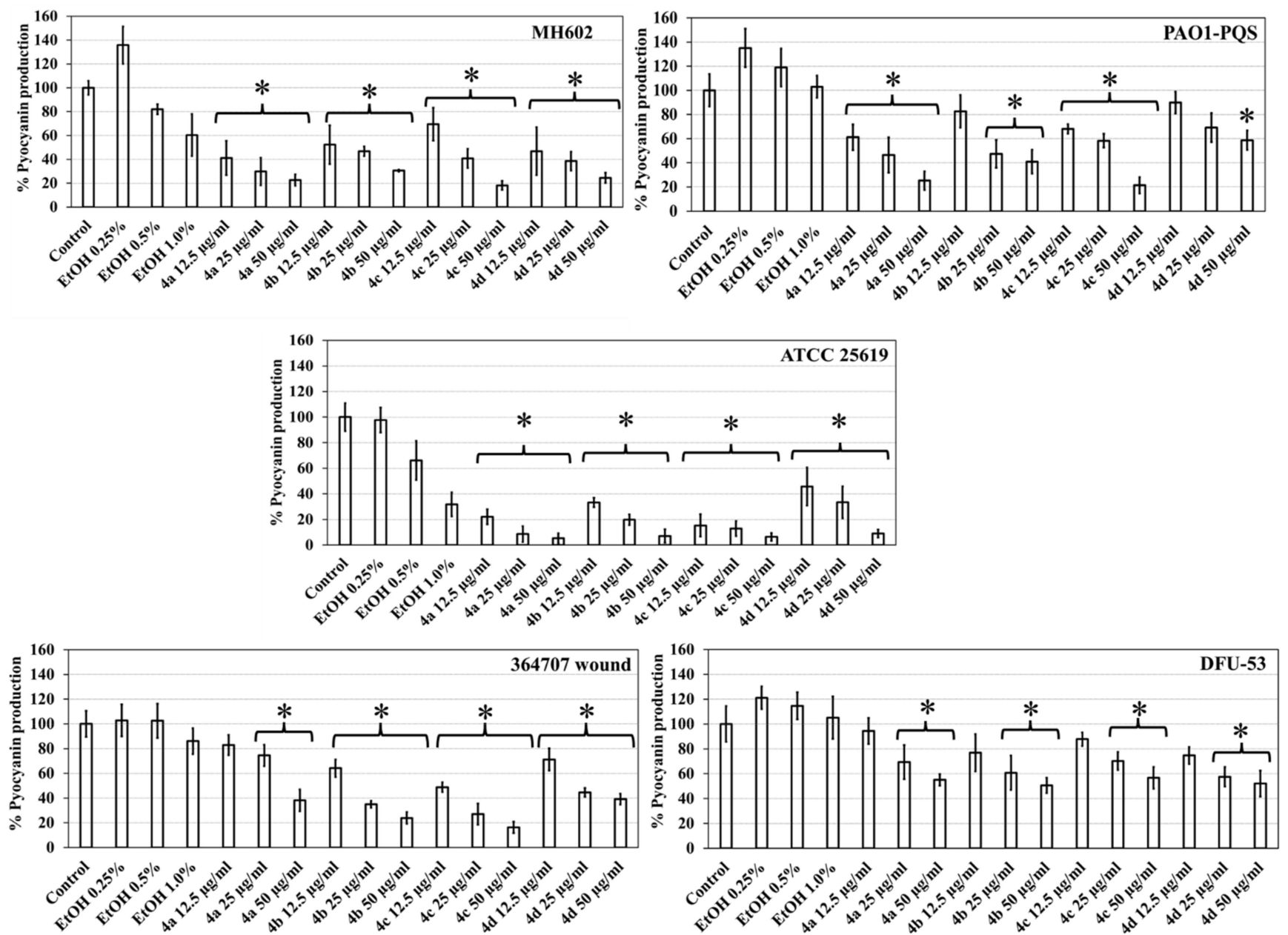

Figure 5. Inhibition of pyocyanin production by P. aeruginosa by DHP compounds. * Indicates differences are statistically significant. $p<0.05$.

\subsection{Cytotoxicity Study of DHP Analogues $4 a$ and $4 c$ on Human Foreskin Fibroblasts (HFF-1)}

Due to the overall performance of compounds $4 \mathbf{a}(\mathbf{B r})$ and $4 \mathbf{c}(\mathbf{F})$, these were tested for their cytotoxicity. Resazurin cell metabolic assay and microscopy images confirmed 
that compounds $4 \mathbf{a}(\mathbf{B r})$ at 12.5 and $25 \mu \mathrm{g} / \mathrm{mL}$ and $4 \mathbf{c}(\mathbf{F})$ at $25 \mu \mathrm{g} / \mathrm{mL}$ produced no cytotoxicity on human foreskin fibroblast (HFF-1) cells after $24 \mathrm{~h}$ incubation. The cell morphology and confluence remained similar to the control, whereas the positive control of $100 \%$ DMSO produced severely disrupted cell morphology (Figure 6A). Cell viability was $100-94 \%$ with 12.5 and $25 \mu \mathrm{g} / \mathrm{mL}$ of the compounds, but reduced to $67-72 \%$ at $50 \mu \mathrm{g} / \mathrm{mL}$ (Figure 6B). When HFF-1 was exposed to the positive control DMSO, its viability decreased to $<20 \%$. Negative controls, where HFF-1 cells were treated with $0.9 \% \mathrm{NaCl}$, showed full confluence of cells and $100 \%$ viability. Cell viability is representative of the average from three biological replicates.
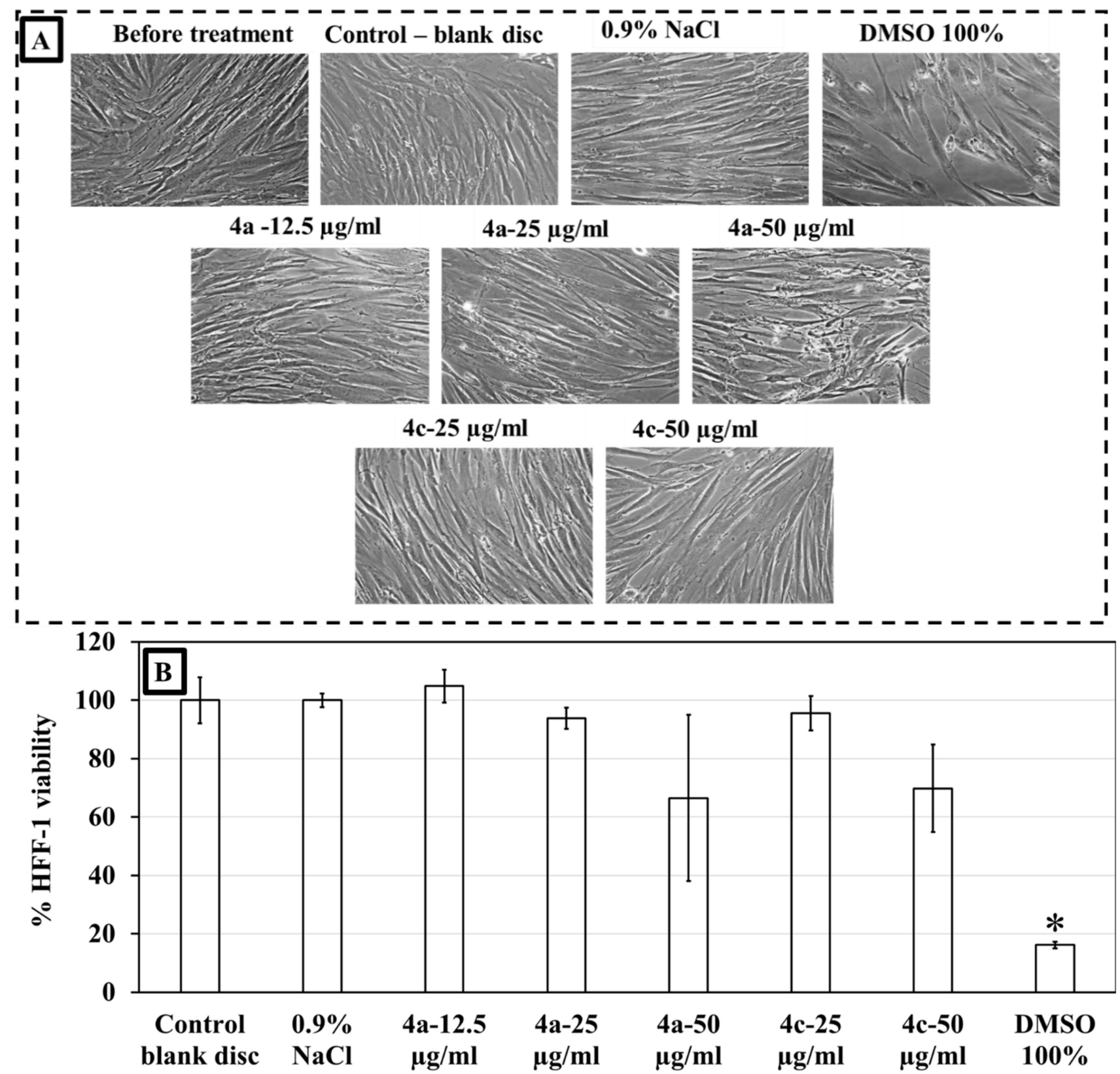

Figure 6. Cytotoxic effects of DHP 4a (Br) and 4c (F) and DMSO on HFF-1 cells. (A) Microscopic images showing morphology of HFF-1 cells and (B) Metabolic viability of HFF-1 cells. * Indicates differences were statistically significant $p<0.05$. 


\section{Discussion}

Inhibition of QS with the aim of disrupting virulence factor production and biofilm formation is a key strategy to prevent bacterial pathogenicity. The current study evaluated QS inhibition by DHP analogues. DHP compounds had a concentration-dependent inhibitory effect on the AHL and PQS QS systems of P. aeruginosa. When treated with the DHP analogues, there was a reduction in the production of GFP that was linked to LasR and PqsR receptor proteins, as well as the production of phenazine and biofilm. LasR binds its cognate ligand AHL/HSL to trigger its activation and the transcription of various genes, including those associated with the production of virulence factors [3,4]. PqsR binds to the PQS signaling molecule 2-heptyl-3-hydroxy-4-quinolone and then transcribes phenazine synthesis genes (PhzA1-G1 and A2-G2) [3]. The QS systems in P. aeruginosa are interconnected with the PQS system being controlled by the LasR-AHL/HSL system [17]. Therefore, inhibition in LasR receptor proteins leads to a decline in PqsR receptors and, ultimately, a reduction in pyocyanin production (Figure 7).

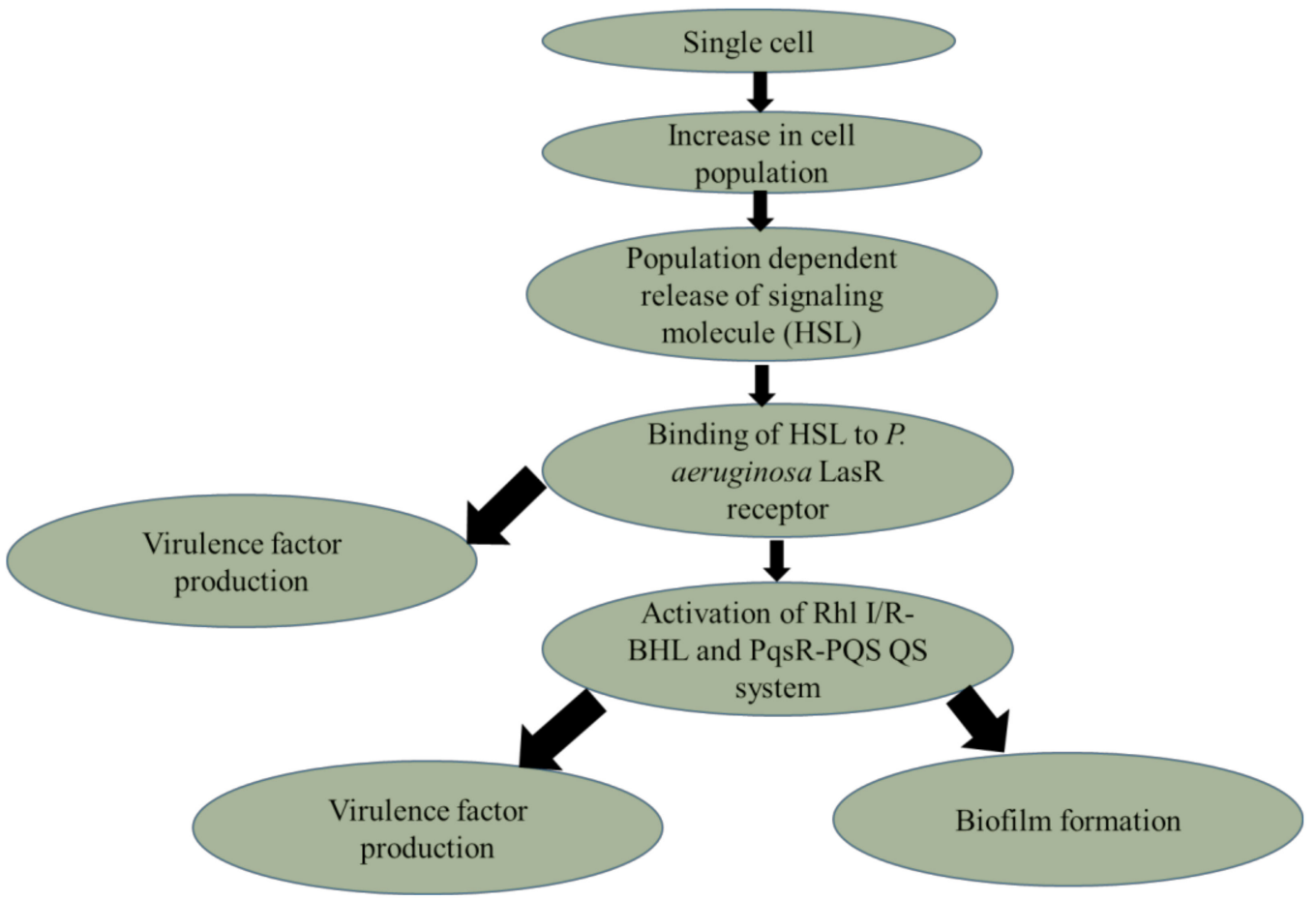

Figure 7. Schematic showing how $P$. aeruginosa QS systems result in virulence factor production and biofilm formation. Binding of AHL/HSL to LasR triggers transcription of Rhl I/R and PqsR and the production of their ligands BHL and PQS. These QS systems then coordinated the biosynthesis of virulence factors such as pyocyanin and the formation of biofilm.

In general, the differences in electronegativity and hydrophobicity of DHP compounds driven by the presence of halogens $(\mathrm{Br}, \mathrm{Cl}$, and $\mathrm{F})$ did not significantly affect pyocyanin production or biofilm formation, but did affect activation of the PqsR receptor. Compound 4a, containing bromine, inhibited the production of GFP by PqsR between two- $($ at $12.5 \mu \mathrm{g} / \mathrm{mL})$ and eight-(at $50 \mu \mathrm{g} / \mathrm{mL})$ fold. Compound $4 \mathbf{b}$, containing chlorine, reduced the production of GFP by PqsR by one- to two-fold, and compound 4c, containing fluorine, reduced production by one- to nine-fold. Studies have shown that pyocyanin production is directly related to virulence and severity of infection $[18,19]$, and so inhibition of pyocyanin would likely reduce pathogenicity in a host.

Another role of pyocyanin is its ability to increase the stability of the P. aeruginosa biofilm matrix by enhancing extracellular DNA production $[20,21]$ and binding with extracellular DNA to form a stable biofilm [10]. In the current study, DHP compounds produced 
an approximately $30 \%$ decrease in biofilm biomass. This decrease may have been due to the reduction in pyocyanin affecting the viscosity of the biofilm matrix. The biofilm matrix viscosity is an essential factor that helps biofilms to be resistant to shear stress and antibacterial agents $[22,23]$. In the case of $P$. aeruginosa, pyocyanin binding to DNA enhances the viscosity of the eDNA biofilm matrix $[10,22]$. A reduction in pyocyanin may weaken the architecture of the biofilm and thus allow the biofilm to slough off from surfaces more easily $[10,24]$.

All DHP compounds produced a drastic decrease in LasR- and PqsR-mediated production of GFP and a significant reduction in pyocyanin, and biofilm formation. Also, compounds 4a and 4c were not cytotoxic as per the ISO 10993-5:2009_direct contact method, on the HFF-1 cell line [25]. Fibroblasts are crucial cell lines for wound healing. Data from the current study indicate that when administrated responsibly or at a moderate concentration of $25 \mu \mathrm{g} / \mathrm{mL}$, DHPs have the potential to reduce P. aeruginosa pathogenicity by minimizing virulence factor production and impairing biofilm formation, with limited cytotoxicity to human cells. Previous studies have shown that DHP compounds combined with antibiotics increase the susceptibility of P. aeruginosa to those antibiotics [26,27], and this may further increase their utility. However, a study has demonstrated that recurrent exposure of $P$. aeruginosa PAO1 biofilms to a combination of the furanone (C-30), an inhibitor of the LasR/I system, and tobramycin resulted in an increased resistance triggered by mutation or deletion in antibiotic resistance genes (mexT, fusA1, and parS) [27]. The current compounds should be analyzed similarly to determine whether they are also associated with increased resistance to conventional antibiotics.

\section{Materials and Methods}

\subsection{Synthesis}

All the DHP analogs have been synthesized in sequential steps by previously reported protocols. Synthesis commences through a condensation reaction between commercially available halogenated derivatives of phenylacetone (1) and glyoxylic acid in the presence of phosphoric acid, which gives a lactone intermediate (2). This lactone is converted into the corresponding lactam analog (3) in two steps, including heating with thionyl chloride followed by reaction with aqueous ammonia. The final step involves dehydration of the 5-hydroxy-lactam compound by phosphorous pentoxide $\left(\mathrm{P}_{2} \mathrm{O}_{5}\right)$, which yields the target 5-methylene-4-phenyl- 1,5-dihydro-2H-pyrrol-2-ones (4) (Figure 8) [28,29].

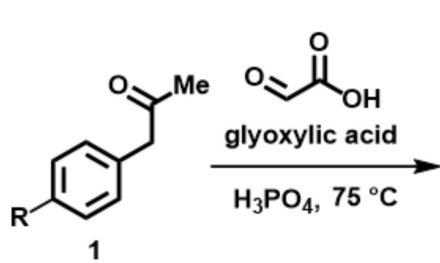

1

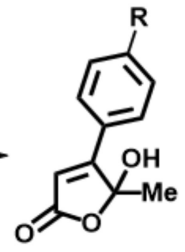

2
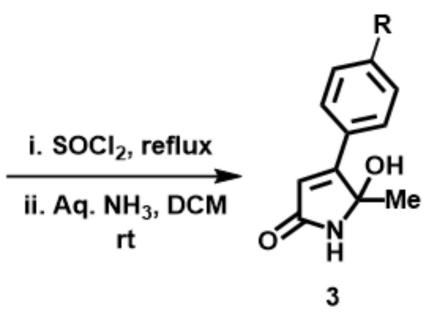
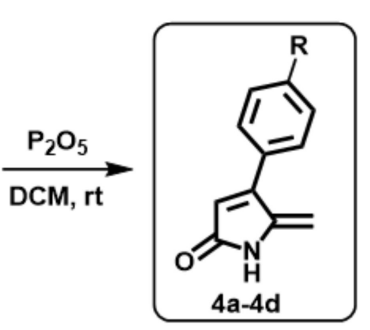

Figure 8. Step-by-step synthesis of halogenated dihydropyrrol-2-one molecules. Compound ID and respective halogen atom labelled as " $\mathrm{R}$ ".

\subsection{P. aeruginosa Isolates, Culture and Growth Conditions}

$P$. aeruginosa strains used in this study included $P$. aeruginosa MH602 lasB::gfp(ASV) for LasR analysis and PAO1 pqsA::gfp for PqsR analysis, ATCC 25619, and clinical isolates DFU-53 (high-risk foot clinic, Liverpool Hospital, Sydney, NSW, Australia) and 364707 (a head wound isolate from the Microbiology Department, Royal Prince Alfred Hospital, Sydney, NSW Australia). All clinical isolates were patient de-identified before being gifted to us from the hospitals. Clinical bacteria from patients were previously isolated and characterized by qualified pathologists from the respective hospitals based on procedures detailed 
in ASM Clinical Microbiology Procedures Handbook-4th Edition, ASM Press (edited by Amy L. Leber). None of the authors were involved in the isolation or characterization of clinical isolates from patients. Bacterial isolates, once received in our research laboratory, were immediately grown in a full-strength (100\%) Tryptone Soy Broth (Oxoid, ThermoFisher, Sydney, NSW, Australia) in a test tube at $37^{\circ} \mathrm{C}, 150 \mathrm{rpm}$ for $24 \mathrm{~h}$. Following $24 \mathrm{~h}$ of growth, the bacterial stock was prepared by mixing $1.2 \mathrm{~mL}$ of bacterial culture with $400 \mu \mathrm{L}$ of DMSO $(100 \%)$, and stored in $2 \mathrm{~mL}$ of the cryogenic vials (Corning, Sigma-Aldrich, Sydney, NSW, Australia) at $-80{ }^{\circ} \mathrm{C}$. To note: the final concentration of DMSO in the bacterial stock is $25 \%$. $P$. aeruginosa isolates from the frozen stock were plated as required onto Tryptone Soy agar (Oxoid) and grown for $24 \mathrm{~h}$ by incubating at $37^{\circ} \mathrm{C}$. Further growth was initiated by striking a colony from the Tryptone Soy agar plate into the $5 \mathrm{~mL}$ of Muller-Hinton Broth (MHB; Oxoid) for $24 \mathrm{~h}$ at $37^{\circ} \mathrm{C}$, with orbital shaking at $150 \mathrm{rpm}$ for all experiments.

\subsection{P. aeruginosa Isolates' Susceptibility to Ciprofloxacin}

The antibiotic susceptibility of all $P$. aeruginosa strains used in this study was tested aganist ciprofloxacin. A stock of ciprofloxacin $(100 \mu \mathrm{g} / \mathrm{mL})$ was prepared by dissolving it in MHB. P. aeruginosa strains were grown for $24 \mathrm{~h}$ at $37^{\circ} \mathrm{C}, 150 \mathrm{rpm}$ in $5 \mathrm{~mL} \mathrm{MHB}$, as mentioned above. After $24 \mathrm{~h}$ of growth, each $P$. aeruginosa culture was diluted (by resuspending in $\mathrm{MHB}$ to a density of $\left.0.15 \pm 0.04\left(\mathrm{OD}_{600 \mathrm{~nm}}\right)\right)$, either in the presence or absence of ciprofloxacin $(1,2$, and $5 \mu \mathrm{g} / \mathrm{mL})$. Then, $200 \mu \mathrm{L}$ of the dilute P. aeruginosa culture (in the presence or absence of ciprofloxacin) was placed in the 96-well plates and the growth was recorded by measuring the absorbance at $\mathrm{OD}_{600 \mathrm{~nm}}$ at 0 after $24 \mathrm{~h}$ incubation at $37^{\circ} \mathrm{C}$. Any increase in growth at $24 \mathrm{~h}$ was determined by subtracting the absorbance readings obtained at $0 \mathrm{~h}$.

\subsection{LasR and PqsR Detection and Growth Quantification}

P. aeruginosa MH602 lasB::gfp(ASV) and PAO1 pqsA::gfp isolates were grown overnight in $\mathrm{MHB}$, supplemented with $30 \mu \mathrm{g} / \mathrm{mL}$ gentamicin at $37^{\circ} \mathrm{C}, 150 \mathrm{rpm}$ [30,31]. Additionally, $500 \mu \mathrm{L}$ of bacterial culture (grown overnight in MHB) was further diluted in M9 minimal salt media (Sigma-Aldrich, Sydney, NSW, Australia) to a total volume of $5 \mathrm{~mL}$, either in the presence or absence of DHP compounds $(12.5,25$, and $50 \mu \mathrm{g} / \mathrm{mL})$. For untreated control and to test the impact of solvent, PBS and ethanol (equivalent to respective DHP concentrations), respectively, were used in place of DHP compounds. The final bacterial cell density in $5 \mathrm{~mL}$ of diluted culture was approximately $0.1 \pm 0.025$ at $\mathrm{OD}_{600 \mathrm{~nm}}$, measured using a plate reader (Tecan infinite M1000 Pro, ThermoFisher, Australia). M9 minimal media was chosen due to its low autofluorescence in comparison to MHB and Tryptone soy broth. Finally, $200 \mu \mathrm{L}$ of diluted M9 minimal salt medium was dispensed into 96-well plates (Corning Corp., Corning, NY, USA) and incubated at $37^{\circ} \mathrm{C}$ with orbital shaking at $150 \mathrm{rpm}$. Production of GFP via the receptor proteins LasR and PqsR and bacterial growth was monitored every hour for up to $10 \mathrm{~h}$ by measuring fluorescence at $\mathrm{Ex}_{485 \mathrm{~nm}}$ and $\mathrm{Em}_{535 \mathrm{~nm}}$ and absorbance at $\mathrm{OD}_{600 \mathrm{~nm}}$ for LasR and PqsR and bacterial growth, respectively. Bacterial growth $\left(\mathrm{OD}_{600 \mathrm{~nm}}\right)$ was further measured after $24 \mathrm{~h}$ and $48 \mathrm{~h}$ of treatment. To quantify LasR and PqsR expression, the GFP fluorescence values measured at every time point were divided by their respective $\mathrm{OD}_{600 \mathrm{~nm}}$ absorbance. A graph was plotted as GFP/OD vs. time in hours.

\subsection{P. aeruginosa Biofilm Biomass Quantification Using Crystal Violet}

For assessing biofilm biomass, P. aeruginosa was grown as described above. The bacterial culture $(200 \mu \mathrm{L})$ was aliquoted in 96-well plates at a density of $0.1 \pm 0.025\left(\mathrm{OD}_{600 \mathrm{~nm}}\right)$. The bacteria were incubated for $48 \mathrm{~h}$ at $37^{\circ} \mathrm{C}$ with $150 \mathrm{rpm}$ orbital shaking in M9 minimal media containing $10 \% \mathrm{MHB}$, in the presence or absence of DHP. After $48 \mathrm{~h}$, the supernatant was removed and the biofilm was washed once with phosphate-buffered saline (PBS; $137 \mathrm{mM} \mathrm{NaCl}, 2.7 \mathrm{mM} \mathrm{KCl}$ and $10 \mathrm{mM}$ phosphate, pH 7.41, POCD Healthcare, North Rocks, NSW, Australia) to remove any loosely bound bacterial cells. The attached biofilms 
were then treated with $0.01 \%$ crystal violet dye and incubated for $60 \mathrm{~min}$ at $37^{\circ} \mathrm{C}$ and $150 \mathrm{rpm}$. After $60 \mathrm{~min}$, excess dye was removed by washing with PBS three times. The plates were then dried for $20 \mathrm{~min}$ at $37^{\circ} \mathrm{C}$, followed by the addition of $200 \mu \mathrm{L}$ of $80 \%$ ethanol and incubation for $30 \mathrm{~min}$ at $37^{\circ} \mathrm{C}$, with orbital shaking at $150 \mathrm{rpm}$ to dissolve the dye from the biofilm biomass. Aliquots $(100 \mu \mathrm{L})$ of dye were transferred to a new 96-well plate, to which $100 \mu \mathrm{L}$ of PBS was added to make up a total volume of $200 \mu \mathrm{L}$ in each well. The plates were then analyzed for biofilm biomass by measuring absorbance at OD $_{550 \mathrm{~nm}}$ using a plate reader. As mentioned in Section 4.4, the controls were growth in the absence of DHP and in the presence of the equivalent amount of DHP solvent (ethanol).

\subsection{Quantification of Pyocyanin Production}

All P. aeruginosa strains were grown overnight in MHB, except for PAO1 and MH602, which were grown in MHB supplemented with $30 \mu \mathrm{g} / \mathrm{mL}$ gentamicin, at $37^{\circ} \mathrm{C}$ with orbital shaking at $150 \mathrm{rpm}$. Bacterial cultures grown in MHB were diluted to a total of $5 \mathrm{~mL}$ of M9 minimal salt media in presence or absence of DHP $12.5,25$, and $50 \mu \mathrm{g} / \mathrm{mL}$ and PBS or DHP ethanol solvent to a density of $0.1 \pm 0.025\left(\mathrm{OD}_{600 \mathrm{~nm}}\right)$ and incubated for $48 \mathrm{~h}$ at $37{ }^{\circ} \mathrm{C}$ with $150 \mathrm{rpm}$ orbital shaking. After $48 \mathrm{~h}$, cultures were transported in a sterile $15 \mathrm{~mL}$ Falcon tube and centrifuged at $4500 \mathrm{~g}$ for $10 \mathrm{~min}$ at $10^{\circ} \mathrm{C}$. After centrifugation, the supernatant was removed and pyocyanin was extracted as described previously [32]. In brief, the supernatant was treated with chloroform to a ratio of 1:0.6 (i.e., to every $1 \mathrm{~mL}$ of supernatant, $600 \mu \mathrm{L}$ of chloroform added). The mixture was immediately vortexed for $5 \mathrm{~s}$ and centrifuged for a further $10 \mathrm{~min}$ at $4500 \times g$ at $10{ }^{\circ} \mathrm{C}$. The bottom blue layer was pipetted into sterile $15 \mathrm{~mL}$ Falcon tubes and treated with $0.1 \mathrm{M} \mathrm{HCl}$ at a ratio of 1:0.5 (i.e., $500 \mu \mathrm{L}$ of $0.1 \mathrm{M} \mathrm{HCl}$ was added to every $1 \mathrm{~mL}$ of blue solution). The mixture was vortexed for $5 \mathrm{~s}$, followed by centrifugation for $10 \mathrm{~min}$ at $10{ }^{\circ} \mathrm{C}$ and $4500 \times \mathrm{g}$. An aliquot $(200 \mu \mathrm{L})$ of the final pink top layer composed of acidified pyocyanin was pipetted into wells of a 96-well plate and quantified for pyocyanin by measuring absorbance at OD $_{520 \mathrm{~nm}}$ using a Tecan Infinite M1000 Pro plate reader.

\subsection{Analysis of DHP Cytotoxicity to Human Fibroblast Cells}

After analysis of the results, compounds $4 \mathbf{a}$ and $4 \mathbf{c}$ showed good activities in all assays and thus were chosen to assess their impact on human fibroblast cell lines HFF-1. Cytotoxicity was assessed based on the British Standard ISO 10993-5:2009—direct contact assay [25]. HFF-1 (passage \#14-16) were cultured in DMEM medium supplemented with fetal bovine serum $(12 \% \mathrm{v} / \mathrm{v})$, penicillin $(100 \mathrm{IU} / \mathrm{mL})$, and streptomycin $(100 \mu \mathrm{g} / \mathrm{mL})$. HFF-1 cells were grown at $37{ }^{\circ} \mathrm{C}$ in a $5 \%(v / v) \mathrm{CO}_{2}$ and harvested at $90 \%$ confluence using $0.12 \% v / v$ trypsin-EDTA. Cells were collected by first quenching Trypsin 1:1 v/v with supplemented media and transferred to conical centrifuge tubes, followed by centrifugation $\left(5 \mathrm{~min}, 4500 \times g, 20^{\circ} \mathrm{C}\right.$ ). The supernatant was aspirated, and the cell pellet was suspended in supplemented DMEM media for further experiments.

After harvesting, HFF-1 cells were plated to a density of 105 cells / mL into six-well plates (Corning Corp., Corning, NY, USA) and allowed to incubate at $37{ }^{\circ} \mathrm{C}$ in a $5 \%$ (v/v) CO2 atmosphere, with the medium being exchanged every alternative day until a confluence of $95-100 \%$ of cells (verified using a light microscope) was achieved. At 95-100\% confluence, the medium was discarded and cells were supplemented with $1 \mathrm{~mL}$ of the growth medium, followed by placement of a freshly made filter disc containing $50 \mu \mathrm{L}$ of $4 \mathrm{a}$ $(12.5,25$, and $50 \mu \mathrm{g} / \mathrm{mL})$ or $4 \mathrm{c}(25$ and $50 \mu \mathrm{g} / \mathrm{mL})$ in the center of the wells. The filter disc was prepared by adding $50 \mu \mathrm{L}$ of test compounds directly onto $6 \mathrm{~mm}$ antibiotic filter paper discs and incubating them at room temperature for $2 \mathrm{~h}$ to allow the discs to absorb test compounds. The plates containing HFF-1 and the filter disc were then incubated for $24 \mathrm{~h}$ at $37{ }^{\circ} \mathrm{C}$ in a $5 \%(\mathrm{v} / \mathrm{v}) \mathrm{CO} 2$ atmosphere. After $24 \mathrm{~h}$, the filter disc and the cell growth media were removed and replaced with $1 \mathrm{~mL}$ sterile PBS. The cell morphology of the HFF-1 cells and their confluence were assessed using a light microscope. 
Quantification of HFF-1 cell metabolic activity (a cell viability assay) was analyzed by adding to the cells $50 \mu \mathrm{L}$ of $0.05 \%$ resazurin solution (Sigma-Aldrich, Sydney, NSW, Australia; prepared in sterile MilliQ water) to $1 \mathrm{~mL}$ PBS and incubating them for $24 \mathrm{~h}$ at $37{ }^{\circ} \mathrm{C}$ in a $5 \%(v / v) \mathrm{CO}_{2}$. After $24 \mathrm{~h}$, the fluorescence of the HFF-1 cells was measured at $\mathrm{Ex}_{544 \mathrm{~nm}}$ and Em${ }_{590 \mathrm{~nm}}$ using a plate reader. For the controls, a filter disc containing $50 \mu \mathrm{L}$ $0.9 \% w / v \mathrm{NaCl}$ and another containing $50 \mu \mathrm{L} \mathrm{100 \%} \mathrm{DMSO}$ (a positive control that causes cells death) were used. Based on ISO 10993-5:2009 [25], DHP compounds were considered non-cytotoxic if the viability of cells remained above $80 \%$ (grade 0 ) and mild if cell lysis is not more than 50\% (grade 2). Experiments were conducted in biological triplicates.

\subsection{Statistical Analysis}

For all statistical analysis, GraphPad Prism (https: / www.graphpad.com/quickcalcs / ttest1.cfm (accessed on 23 December 2021)) was used for conducting two-tailed unpaired $t$-tests in order to determine the $p$-values. The data presented are of the mean \pm standard deviation (SD), with $p$-values $<0.05$ deemed as significant.

\section{Conclusions}

Developing compounds that inhibit QS is a strategy to reduce the production of virulence factors as well as biofilm formation (and hence limit antibiotic use) to combat bacterial infections. DHPs have a significant impact on isolates of P. aeruginosa by inhibiting virulence factor (pyocyanin) production and biofilm formation whilst having low cytotoxicity to human fibroblasts. This current study needs to be extended to elucidate the resistance potential of $P$. aeruginosa after repeat exposure to DHP and whether exposure to DHPs can change their antibiotic susceptibility profile. Further, an exploration of how DHPs affect transcription of the genome of $P$. aeruginosa would provide valuable additional information.

Supplementary Materials: The following are available online, Table S1: the average pyocyanin production range by $P$. aeruginosa when grown in presence of DHPs at concentrations ranging from 12.5 to $50 \mu \mathrm{g} / \mathrm{mL}$.

Author Contributions: Experiments, T.D. and S.S.; methodology, T.D., S.S., and R.C.; data analysis, T.D. and S.S.; investigation, T.D. and S.S.; resources, T.D., F.H.K. and S.S.; writing and draft manuscript: T.D., F.H.K. and S.S. review and editing, all authors; supervision, N.K. and M.D.P.W.; project administration, T.O.G., J.F., J.M., N.K., and M.D.P.W.; funding acquisition, J.M., T.D., T.O.G., and G.S.W. All authors have read and agreed to the published version of the manuscript.

Funding: This research was funded by the Department of Industry, Innovation and Science (Innovative Manufacturing CRC Ltd.), Australia and Whiteley Corporation, NSW, Australia co-funded project grant $A$ Novel approach to Biofilm Disruption and Removal, grant number IMCRC/WLY/08052019.1. The work was supported by a Discovery Project from the Australian Research Council grant DP180100845.

Institutional Review Board Statement: Not applicable. No human or animals involved in this study. Informed Consent Statement: Not applicable.

Data Availability Statement: Not applicable.

Acknowledgments: We would like to thank the Microbiology Department at Royal Prince Alfred Hospital, Sydney, Australia for providing the clinical 364707 head wound P. aeruginosa isolate. We also would like to thank Matthew Malone from the High-Risk Foot Clinic, Liverpool Hospital, NSW, Australia for providing the diabetic foot ulcer (DFU-53) isolate. Shekh Sabir would like to thank UNSW for a TFS scholarship.

Conflicts of Interest: The authors G.S.W., J.F., F.H.K., and T.O.G. are employed by Whiteley Corporation. All other authors declare no competing interests. 


\section{References}

1. World Health Organization. Available online: https://www.who.int/news/item/27-02-2017-who-publishes-list-of-bacteria-forwhich-new-antibiotics-are-urgently-needed (accessed on 25 December 2021).

2. Centres for Diseases Control and Prevention. Available online: https://www.cdc.gov/hai/organisms/pseudomonas.html (accessed on 25 December 2021).

3. Lee, J.; Zhang, L. The hierarchy quorum sensing network in Pseudomonas aeruginosa. Prot. Cell 2015, 6, 26-41. [CrossRef] [PubMed]

4. Das, T. Pseudomonas aeruginosa Secreted Biomolecules and Their Diverse Functions in Biofilm Formation and Virulence. In Pseudomonas aeruginosa-Biofilm Formation, Infections and Treatments, 1st ed.; Das, T., Ed.; InTechOpen Limited: London, UK, 2021; pp. 55-73.

5. Wilson, R.; Sykes, D.A.; Watson, D.; Rutman, A.; Taylor, G.W.; Cole, P.J. Measurement of Pseudomonas aeruginosa phenazine pigments in sputum and assessment of their contribution to sputum sol toxicity for respiratory epithelium. Infect. Immun. 1988, 56, 2515-2517. [CrossRef] [PubMed]

6. Muller, M.; Li, Z.; Maitz, P.K. Pseudomonas pyocyanin inhibits wound repair by inducing premature cellular senescence: A role for p38 mitogen-activated protein kinase. Burns 2009, 35, 500-508. [CrossRef] [PubMed]

7. Das, T.; Simone, M.; Ibugo, A.; Witting, P.; Manefield, M.; Manos, J. Glutathione enhances antibiotic efficiency and effectiveness of DNase I in disrupting Pseudomonas aeruginosa biofilms while also inhibiting pyocyanin activity, thus facilitating restoration of cell enzymatic activity, confluence and viability. Front. Microbiol. 2017, 8, 2429. [CrossRef] [PubMed]

8. O'Malley, Y.Q.; Reszka, K.J.; Spitz, D.R.; Denning, G.M.; Britigan, B.E. Pseudomonas aeruginosa pyocyanin directly oxidizes glutathione and decreases its levels in airway epithelial cells. Am. J. Physiol. Lung Cell Mol. Physiol. 2004, 287, L94-L103. [CrossRef]

9. Denning, G.M.; Wollenweber, L.A.; Railsback, M.A.; Cox, C.D.; Stoll, L.L.; Britigan, B.E. Pseudomonas pyocyanin increases interleukin-8 expression by human airway epithelial cells. Infect. Immun. 1998, 66, 5777-5784. [CrossRef]

10. Das, T.; Kutty, S.K.; Tavallaie, R.; Ibugo, A.I.; Panchompoo, J.; Sehar, S.; Aldous, L.; Yeung, A.W.S.; Thomas, S.R.; Kumar, N.; et al. Phenazine virulence factor binding to extracellular DNA is important for Pseudomonas aeruginosa biofilm formation. Sci. rep. 2015, 5, 8398. [CrossRef]

11. Whitchurch, C.B.; Tolker-Nielsen, T.; Ragas, P.C.; Mattick, J.S. Extracellular DNA required for bacterial biofilm formation. Science 2002, 295, 1487. [CrossRef]

12. Saunders, S.H.; Tse, E.C.; Yates, M.D.; Otero, F.J.; Trammell, S.A.; Stemp, E.D.A.; Barton, J.K.; Tender, L.M.; Newman, D.K. Extracellular DNA promotes efficient extracellular electron transfer by pyocyanin in Pseudomonas aeruginosa biofilms. Cell 2020, 182, 919-932. [CrossRef]

13. Heurlier, K.; Dénervaud, V.; Haenni, M.; Guy, L.; Krishnapillai, V.; Haas, D. Quorum-sensing-negative (lasR) mutants of Pseudomonas aeruginosa avoid cell lysis and death. J. Bacteriol. 2005, 187, 4875-4883. [CrossRef]

14. Pesci, E.C.; Pearson, J.P.; Seed, P.C.; Iglewski, B.H. Regulation of las and rhl quorum sensing in Pseudomonas aeruginosa. J. Bacteriol. 1997, 179, 3127-3132. [CrossRef] [PubMed]

15. Sabir, S.; Yu, T.T.; Kuppusamy, R.; Almohaywi, B.; Iskander, G.; Das, T.; Willcox, M.D.P.; Black, D.S.; Kumar, N. Novel seleno- and thio-urea containing dihydropyrrol-2-one analogues as antibacterial agents. Antibiotics 2021, 10, 321. [CrossRef] [PubMed]

16. Grandclément, C.; Tannières, M.; Moréra, S.; Dessaux, Y.; Faure, D.D. Quorum quenching: Role in nature and applied developments. FEMS Microbiol. Rev. 2016, 40, 86-116. [CrossRef] [PubMed]

17. Schertzer, J.W.; Boulette, M.L.; Whiteley, M. More than a signal: Non-signaling properties of quorum sensing molecules. Trends Microbiol. 2009, 17, 189-195. [CrossRef] [PubMed]

18. Hu, Y.; Peng, W.; Wu, Y.; Li, H.; Wang, Q.; Yi, H.; Zhang, R.; Shao, B.; Zhu, K. A potential high-risk clone of Pseudomonas aeruginosa ST463. Front. Microbiol. 2021, 12, 670202. [CrossRef]

19. Fothergill, J.; Panagae, S.; Hart, C.A.; Walshaw, M.J.; Pitt, T.L.; Winstanley, C. Widespread pyocyanin over-production among isolates of a cystic fibrosis epidemic strain. BMC Microbiol. 2007, 7, 45. [CrossRef]

20. Das, T.; Manefield, M. Pyocyanin promotes release of extracellular DNA in Pseudomonas aeruginosa. PLoS ONE 2012, 7, e46718. [CrossRef]

21. Meirelles, L.A.; Newmann, D.K. Both toxic and beneficial effects of pyocyanin contribute to the lifecycle of Pseudomonas aeruginosa. Mol. Microbiol. 2018, 110, 995-1010. [CrossRef]

22. Peterson, B.W.; van der Mei, H.C.; Sjollema, J.; Busscher, H.J.; Sharma, P.K. A distinguishable role of eDNA in the viscoelastic properties of biofilms. mBio 2013, 4, e00497-13. [CrossRef]

23. Peterson, B.W.; He, Y.; Ren, Y.; Zerdoum, A.; Libera, M.R.; Sharma, P.K.; van Winkelhoff, A.-J.; Neut, D.; Stoodely, P.; van der Mei, H.C.; et al. Viscoelasticity of biofilms and their recalcitrance to mechanical and chemical challenges. FEMS Microbiol. Rev. 2015, 39, 234-245. [CrossRef]

24. Dietrich, L.E.P.; Teal, T.K.; Price-Whelan, A.; Newman, D.K. Redox-active antibiotics control gene expression and community behavior in divergent bacteria. Science 2008, 29, 1203-1206. [CrossRef] [PubMed]

25. Biological Evaluation Of Medical Devices-ISO 10993-5:2009_Part 5: Tests For In Vitro Cytotoxicity. Available online: https: / / www.iso.org/standard/36406.html. (accessed on 25 December 2021). 
26. Christensen, L.D.; van Gennip, M.; Jakobsen, T.H.; Alhede, M.; Hougen, H.P.; Høiby, N.; Bjarnsholt, T.; Givskov, M. Synergistic antibacterial efficacy of early combination treatment with tobramycin and quorum-sensing inhibitors against Pseudomonas aeruginosa in an intraperitoneal foreign body infection mouse model. J. Antimicrob. Chemother. 2012, 67, 1198-1206. [CrossRef] [PubMed]

27. Bové, M.; Bao, X.; Sass, A.; Crabbé, A.; Coenye, T. The quorum-sensing inhibitor furanone C-30 rapidly loses its tobramycinpotentiating activity against Pseudomonas aeruginosa biofilms during experimental evolution. Antimicrob. Agents Chemother. 2021, 65, e00413-21. [CrossRef] [PubMed]

28. Kumar, N.; Iskander, G. Novel lactams. International Patent Application WO2007085042A1, 2 August 2007.

29. Almohaywi, B.; Yu, T.T.; Iskander, G.; Chan, D.S.H.; Ho, K.K.K.; Rice, S.; Black, D.S.; Griffith, R.; Kumar, N. Dihydropyrrolones as bacterial quorum sensing inhibitors. Bioorg. Med. Chem. Lett. 2019, 29, 1054-1059. [CrossRef] [PubMed]

30. Yang, L.; Barken, K.B.; Skindersoe, M.E.; Christensen, A.B.; Givskov, M.; Tolker-Nielsen, T. Effects of iron on DNA release and biofilm development by Pseudomonas aeruginosa. Microbiolology 2007, 153, 1318-1328. [CrossRef] [PubMed]

31. Sabir, S.; Suresh, D.; Subramoni, S.; Das, T.; Bhadbhade, M.; Black, D.S.; Rice, S.A.; Kumar, N. Thioether-linked dihydropyrrol-2one analogues as PqsR antagonists against antibiotic resistant Pseudomonas aeruginosa. Bioorg. Med. Chem. 2021, $31,115967$. [CrossRef]

32. Essar, D.W.; Eberly, L.; Hadero, A.; Crawford, I.P. Identification and characterization of genes for a second anthranilate synthase in Pseudomonas aeruginosa: Interchangeability of the two anthranilate synthases and evolutionary implications. J. Bacteriol. 1990, 172, 884-900. [CrossRef] 